\title{
Categorias intuitivas para o ensino do Cálculo: descrição e implicações para o seu ensino
}

Francisco Regis Vieira Alves fregis@ifce.edu.br

0000-0003-3710-156

Instituto Federal de Educação, Ciência e Tecnologia do Estado do Ceará - IFCE. Programa de Pós-graduação em Ensino de Ciências e Matemática - IFCE.
RESUMO

A aprendizagem de um indivíduo possui marco inicial em um raciocínio lógico-formal ou em um raciocínio intuitivo? Se a resposta para tal questionamento apontar na direção do raciocínio intuitivo surge, pois, um segundo questionamento: Mas o que é mesmo um raciocínio intuitivo? Com atenção em responder essa última pergunta, e outras que decorrem, de modo natural, adota-se a perspectiva de Fischbein (1987), no que concerne a uma proposta de descrição de categorias para a intuição. Assim, dá-se ênfase em sua significação no contexto de resolução de problemas do Cálculo Diferencial e Integral. A consideração de tais categorias intuitivas adquire importância na medida em que se propõe uma abordagem que se apoia na tecnologia no sentido de promover a visualização e, consequentemente, a produção de sentenças proposicionais, oriundas da relação entre sujeito/objeto. Por fim, nos exemplos (integrais generalizadas e o teorema da função implícita) são indicadas perspectivas que atuam no sentido de suavizar os efeitos arbitrários do formalismo.

PALAVRAS-CHAVE: Intuição. Cálculo. Resolução de Problemas. Categorias intuitivas. 


\section{INTRODUÇÃO}

Por séculos, vários matemáticos buscaram uma prova para o emblemático 5o postulado euclidiano. Apesar de parecer "correto, não se mostra claramente evidente. O problema básico com esse postulado - não importando a forma pela qual é expresso - é que admite, implícita ou explicitamente, a possibilidade de retas infinitas" (FISCHBEIN, 1987, p. 63).

Reparemos que o objeto de grande atenção por alguns matemáticos no passado foi apenas o 5 o postulado euclidiano, entretanto, sublinhamos que o caráter de "evidência" não pode ser uma qualidade intrínseca a esse objeto. Pois, se tal fato fosse verdadeiro, qualquer matemático (ou observador ordinário comum), ao contemplar e direcionar sua atenção, sua atividade intelectiva ao referido objeto desenvolveria, consequentemente, o mesmo sentimento (sensação), o qual detém um caráter privado, subjetivo, condicionado de modo idiossincrásico. Aquele jargão matemático, corriqueiramente repetido que diz: "Há, é fácil ver!" . Poderia ser, pois, generalizado. Entretanto, na prática, não é bem isso que se pode inferir e replicado em outras circunstancias.

Daí, depreendemos que o termo "evidência" não se refere a um fator qualitativo, particular e vinculado ao objeto. E sim, afirmamos, originadamente de uma relação que se estabelece entre sujeito-objeto, num momento inicial e de modo tácito. Cabe assinalar, também, no excerto em destaque por Fischbein, que o termo "correto" é vinculado, de modo subliminar, a um determinado corpus teórico estruturante e formal, que confere a determinada sentença proposicional (de estrutura inferencial), o caráter de credibilidade, consistência e elimina consideravelmente uma chance de dúvida, incerteza ou perquirição ulterior.

Os termos colocados em destaque ("evidência" e "corretude" ou ainda "consistência") detêm uma natureza eminentemente filosófica, e podem indicar/produzir questões de densa natureza, no campo da Filosofia da Matemática (ERNEST, 1991; RUSSELL, 1993). Todavia, restringiremos nossa atenção ao campo da Psicologia Cognitiva, visto que, quando falamos de raciocínio matemático e sua natureza, não podemos permanecer limitados apenas à Matemática Pura.

Por fim, cabe evidenciar que o problema de pouca nitidez, para alguns, e de relevância indubitável, para outros, refere-se à base do raciocínio (intuitivo) empregado no passado, com a intenção de investigar e compreender o problema do 5 o postulado euclidiano. Assim, com origem nessa pequena reflexão preambular, nesse artigo, discutiremos várias questões relacionadas com a hierarquização e descrição de categorias do raciocínio intuitivo. Com base nesse exemplo apontado por Fischbein (1987, p. 63) e em outros registrados em pesquisas (ALVES, 2016; 2014a; 2012; ALVES \& BORGES NETO, 2011), passaremos a falar não apenas de intuição, mas também, de intuições ou categorias intuitivas no contexto do ensino do Cálculo em Uma e em Várias Variáveis.

$\mathrm{O}$ caráter fortuito a ser destacado, diz respeito à possibilidade de seu uso e exploração intencional, didático-metodológica no ensino de Matemática, com ênfase ao contexto acadêmico. Isso posto, inicialmente acentuaremos determinadas ponderações de Fischbein (1987) sobre o referido assunto, tendo em vista um entendimento preliminar de um terreno de intensa discussão filosófica. 


\section{INTUIÇÃO OU INTUIÇÕES?}

O tipo de categoria intuitiva de conhecimento foi objeto de atenção e reflexão por parte de inúmeros filósofos, como assinala Fischbein (1999, p. 11). Dentre algumas das figuras emblemáticas, vale destacar, nomes como: G. W. Leibniz, R. Descartes, B. Spinoza, E. Kant, F. Kline, H. Bergson, M. Bunge. No rol desses e outros pensadores e filósofos, registramos a diversidade de significados atribuídos à faculdade ontológica cognitiva que nomeamos por intuição.

Seu papel nem sempre é compreendido, apesar de que, as pesquisas matemáticas modernas apresentem dois grandes processos e/ou momentos, indicados por Choquet (1963, p. 3), nomeadamente, como a pesquisa e a síntese. E quando não restringimos nosso olhar à perspectiva bourbakiana (HERSH, 1997, p. 32), com forte ênfase ao caráter estrutural e axiomático, a intuição detém seu papel e pode ser detectada em ambos os momentos investigativos.

"Fonte última para determinadas verdades absolutas" (BUNGE, 1996, p. 34). Estratégia mental que permite alcançar a essência e a manifestação de um fenômeno. Caracterizada ainda por determinadas categorias intelectivas que proporcionam "o entendimento tácito de um teorema" (POINCARÉ, 1921, p. 38), sem uma justificativa ou interpretação sistemática a priori. Faculdade cognitiva que possibilita o alcance e o estabelecimento imediato de ligações entre sujeito cognoscente e um objeto. Por fim, no rol dos significados que podemos registrar na literatura especializada, atribuídos à intuição; vale salientar que, no interior da esfera de práticas vinculadas a determinados saberes científicos, o que nomeamos ou designamos por intuição recebe, por vezes, uma conotação que se contrapõem aos termos e pressupostos reconhecidos na Lógica (OTTE, 1991).

Nesse sentido, Otte (1991, p. 281) explica que "a intuição parece ser o oposto de rigoroso, ou de lógico, ou de formal. A lógica parece ser compreendida, enquanto que a intuição se mostra indefinível". Ademais, na atividade científica, "a intuição torna-se um instrumento poderoso no sentido da inventividade" (HADAMARD, 1945, p. 43) e manifestação de genialidade. Corrobora Hersh (1997, p. 61) conosco, ao lembra que:

Na prática matemática, a intuição está em toda parte. Ele fornece os exemplos de fórmulas de somas infinitas, de frações e produtos, encontrados na carta de Ramannujan à Hardy. Os resultados comprovam a intuição, pois estavam todos corretos, embora não haviam sido provados pelo mesmo.

Ainda sobre a função pedagógica do raciocínio intuitivo, Boutroux (1908), esclarece:

No que concerne a inteligência, uma boa educação aprimora e dirige as faculdades, mais do que forçar a memória. Existem dois exercícios da faculdade: um é livre, é o jogo; o outro imposto é o trabalho. Este último é obrigatório por si mesmo e no ensino não é substituído pelo primeiro. A faculdade da intuição deve ser formada antes do entendimento. Todo o ensino será inicialmente intuitivo, representativo e técnico (BOUTROUX, 1908, p. 394)

Um elemento identificado na teorização desenvolvida por Fischbein diz respeito ao papel e às fontes de explicação da natureza do conhecimento que obtemos por meio da faculdade psíquica que nomeamos de intuição. Efrain Fischbein (1920 - 1998) recorreu tanto ao campo da pesquisa em Psicologia 
Cognitiva como ao terreno filosófico, com vistas à estruturação e o desenvolvimento de suas argumentações. "Ele conseguiu divisar a proficuidade dos problemas que possivelmente exigem respostas de ambas áreas do saber científico" (ALVES \& BORGES NETO, 2011, p. 39).

Antes, todavia, de descrever as categorias do nosso interesse de indagação, surge uma condição sine qua non, referente ao entendimento da natureza/função dos processos cognitivos, com base intuitiva. Para tanto, Fischbein (1999) desenvolve um discurso mais detalhado no artigo intitulado Intuitions and Schemata of Mathematical Reasoning. Nesse artigo, encontramos a delineação do significado de algumas características dos processos de raciocínios intuitivos. Fischbein explica que em tais raciocínios, identificamos:

- Cognições autoevidentes: significam que intuições são aceitas sem que o indivíduo manifeste a necessidade de uma checagem/verificação ou prova $a$ posteriori;

- Convicção intrínseca: diz respeito a uma cognição (de natureza privada) intuitiva usualmente associada ao sentimento de certeza, convicção de segurança;

- Sentido coercitivo: que a intuição manifesta um 'efeito coercitivo' no sentido de afetar as estratégias de raciocínio do indivíduo e sua seleção de hipóteses e soluções. Isto significa que o indivíduo tende a rejeitar/negar interpretações alternativas de outrem, as quais contrariem suas intuições privadas e momentâneas.

- Caráter de globalidade: por fim, uma característica basilar entre um raciocínio intuitivo e um raciocínio lógico é descrita pelo autor, distinguimos o caráter de globalidade, isto é, intuições são cognições globais em oposição às cognições adquiridas por uma via de sequências inferenciais (do tipo: Se vale... Então...) e lógicas ou analítico-inferencial.

Para efeito das situações didáticas que pretendemos descrever e caracterizar possíveis ações e estratégias a serem tomada pelo professor, assinalamos as seguintes categorias intuitivas: intuições afirmativas, intuições conjecturais, intuições antecipatórias e conclusivas. Fischbein assume uma posição que contrasta com a de Piaget, no sentido de classificar as intuições no que concernem suas regras, suas origens e suas relações com outros tipos de cognições, mobilizada pelo sujeito epistêmico.

Fischbein (1987, p. 57) acentua que a classificação proposta por Piaget é muito mais complexa. Ele menciona várias dicotomias. Uma primeira distingue intuições empíricas e operacionais. Uma segunda dicotomia, diz respeito à classe de intuições acompanhadas de imagens, de outras que não apresentam tal propriedade. Desta forma, com o escopo de uma melhor operacionalização das situações que ensejamos acentuar, a descrição de Fischbein nos parece eficiente.

Por outro lado, a adequação da classificação proposta por Fischbein é oportuna, pelo fato de indicar fortes ligações com o processo solucionador de problemas, de cunho investigativo. Assim, explica que nas intuições afirmativas, o elemento solução é implícito. Em contrapartida, as intuições conjecturais possuem elementos próximos da solução (ou estratégia) de uma maneira explicita (identificável), todavia, não envolvidos diretamente no plano ou estratégia de efetiva solução do problema em jogo. 
Para exemplificar, vamos descrever, pois, exemplos dessas categorias intuitivas no contexto de transição interna do Cálculo em Uma Variável Real - CUV para o Cálculo em Várias Variáveis - CVV (ALVES, 2011). No CUV, os estudantes aprendem que toda função $y=f(x)$ derivável será contínua. Tal propriedade é verificada por argumentos formais característicos de um teorema. Já no CVV, eles deparam com ilações do tipo: toda função $z=f(x, y)$ diferenciável será contínua. De acordo a classificação proposta por Fischbein, declarações como essas ultimas são chamadas de intuições afirmativas inferenciais. Todavia, nossa ilação requer ulteriores explicações, balizadas por uma teoria.

De fato, o autor descreve que intuições afirmativas são "representações ou interpretações de vários fatos aceitos como auto evidentes ou autoconsistentes" (FISCHBEIN, 1987, p.58). Ademais, subdivide tal classe, de acordo com o conteúdo semântico, relacional ou inferencial (ver figura 2). Um pouco mais adiante, acentua que "intuições afirmativas inferenciais possuem uma estrutura indutiva ou dedutiva". Após termos encontrado ou identificado certo número de elementos possuindo propriedades em comum tendemos, intuitivamente, a generalizar e a afirmar que toda a categoria desses elementos possui tal propriedade. Ora, um indivíduo pode extrair consequências da assertiva anterior, no contexto do CUV e, acreditar na validade da propriedade sobre a categoria de funções do tipo $z=f(x, y)$ ou $w=f(x, y, z)$, por intermédio da tentativa de uma generalização (nem sempre consciente) da propriedade de diferenciabilidade de funções.

No que tange ao movimento e o sentido de generalização, característico das intuições afirmativas inferenciais, Fischbein (1987, p. 59) explica que "não se trata de uma simples operação lógica. A generalização surge de modo mais ou menos súbito, acompanhado de um sentimento de confiança". Assim, somente ao ser questionado, o sujeito poderá verbalizar, explicar e detalhar o motivo ou razão da ocorrência de determinado feeling ou a impressão psicológica correspondente a uma propriedade matemática particular.

Figura 1 - Situação problema envolvendo categorias intuitivas no ensino de integral.

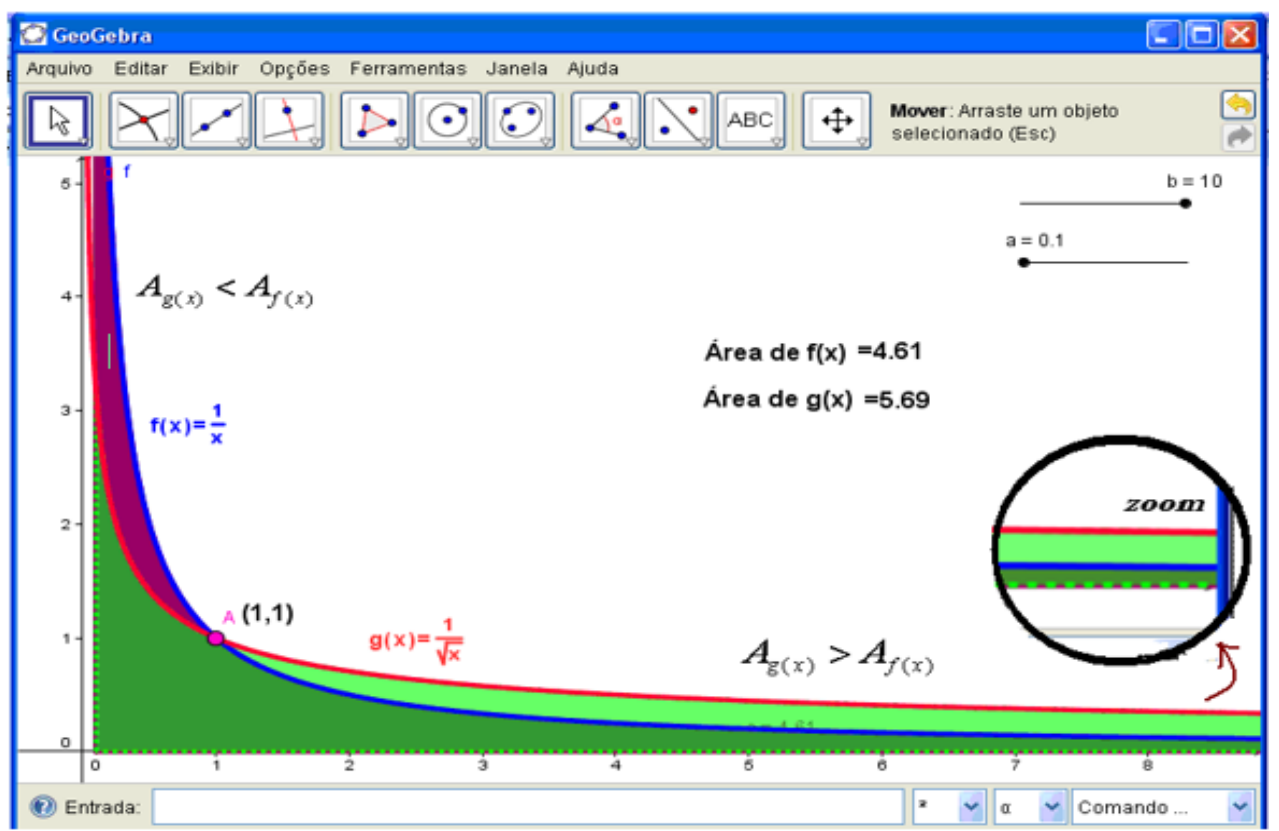

(Fonte: Elaboração do autor) 
Temos também classe de intuições conjecturais que dizem respeito a determinadas declarações sobre eventos futuros, ou sobre o curso e a evolução de certo fenômeno. Tal conjectura é uma intuição quando associada a um elemento de natureza privada e subjetiva, que chamamos de confiança. Sublinhamos o caráter de não trivialidade, no que concerne ao registro de tal categoria intuitiva, no decurso de um fenômeno, fato ou evento. Vejamos, pois, um caso particular de sua ocorrência.

Vamos considerar, pois, a figura 1 anterior. Nela trazemos as funções indicadas $f(x)=\frac{1}{x}$ e $g(x)=\frac{1}{\sqrt{x}}$. No cenário abaixo, indicamos dois elementos que podem proporcionar e estimular a manifestação de elaboração de sentenças proposicionais de um indivíduo, imbuído da intenção de resolução de problemas, no contexto de integrais impróprias. Cabe observar que a manifestação de um discurso é consequência da imediata mobilização de uma espécie de raciocínio, formal ou informal, disparado a partir da percepção (local) e visualização de propriedades gráfico-geométricas (ALVES, 2014b). O caráter manipulatório do software GeoGebra permite a exploração e experimentação (ALVES, 2016). Na figura, o observador deverá observar que, quando consideramos as contribuições de área, para valores $x>1$, notamos que temos as relações entre áreas $A_{g(x)}>A_{f(x)}$. Propriedade que pode ser extraída do comportamento gráficogeométrico, bem como, dos dados numéricos que indicamos do lado direito, por $A_{g(x)}=5.69>A_{f(x)}=4.61$. A percepção exerce papel fundamental (ALVES, 2012, p. 3).

Por outro lado, quando consideramos valores $x \rightarrow 0^{+}($com $0<x<1$ ), notamos que as regiões correspondentes a cada função, $g(x)$ em cor verde e $f(x)$ em cor roxa, ocorrerá uma inversão (a partir do ponto $A=(1,1)$ ) das relações concernentes às contribuições de área $\left(A_{g(x)}<A_{f(x)}\right)$, na medida em que consideramos as contribuições, para valores arbitrariamente próximos de $x=0$, todavia, diferentes de zero. Observamos, entretanto, que não declaramos a existência, nem muito menos o interesse na resolução de um problema particular envolvendo a noção de integral imprópria ou integral definida.

$\mathrm{Na}$ situação que envolve a figura 1, podemos explorar um entendimento dinâmico do processo de convergência/divergência de integrais generalizadas ou integrais impróprias. A variação de cores do software possui um importante componente visual qualitativo. O solucionador pode ser questionado quanto ao significado geométrico de simbologias do tipo $\int_{0}^{1} \frac{d x}{x}, \int_{1}^{\infty} \frac{d x}{x}, \int_{0}^{1} \frac{d x}{\sqrt{x}}$ ou $\int_{1}^{\infty} \frac{d x}{\sqrt{x}}$. No que concerne às intuições conjecturais esperadas neste cenário estruturado com o recurso computacional, o solucionador pode observar as contribuições de área indicadas $\left(-\lim _{t \rightarrow 0^{+}} \int_{t}^{1} d x / x\right)=\lim _{t \rightarrow 0^{+}}[\ln (1)-\ln (t)]=\lim _{t \rightarrow 0^{+}}[\ln (t)]=+\infty$ e, antever que elas tendem a aumentar. Consequentemente, conjecturar que os valores numéricos de área desse limite tendem, paulatinamente e crescer, com base no gráfico (cor roxa), como um caráter inerente ao comportamento de divergência (ALVES, 2012, p. 3), posto que não devem encontrar um número para a determinação do limite anterior. 
Por outro lado, quando analisamos as contribuições de área da integral $\int_{1}^{\infty} \frac{d x}{x}=\lim _{t \rightarrow+\infty} \int_{1}^{t} \frac{d x}{x}$, como base num "trecho" do gráfico (em cor azul) e conjecturar (somente com base na visualização) que as contribuições de área tendem a diminuir, quando comparadas às contribuições de área de $\int_{1}^{\infty} \frac{d x}{\sqrt{x}}=\lim _{t \rightarrow+\infty} \int_{1}^{t} \frac{d x}{\sqrt{x}}$, para valores cada vez maiores de $t \gg 1$ (ver fig. 1). Reparemos que as qualidades sensoriais (cores, altura das regiões e espessura do gráfico) são proporcionadas pelo software e se tornam inexequíveis, quando restringimos nossa mediação didática ao quadro negro (ALVES, 2014b). .

Sem dúvida que a construção que mostramos, também, na figura 1 é estruturada, de modo técnico e conceptual, segundo o corpus teórico que nos permite extrair inferências de caráter lógico formal, como por exemplo, inferir que $\int_{0}^{1} d x / x$ diverge e $\int_{1}^{\infty} d x / x$ divergem, o que contraria a intuição conjectural anterior, ao passo que guiamos nossa investigação com arrimo da visualização. De fato, tais conclusões podem ser reveladas por um estudante de graduação, que manifeste sua ação, de modo restrito, apoiado somente em uma definição formal. Entretanto, em que diferem os processos de conceptuais de raciocínios mobilizados por um marco de referência lógico-formal dos processos de raciocínio que detém um marco original impulsionado pela intuição, visualização e a percepção das propriedades gráfico-geométricas há pouco destacadas?

Num âmbito de discussão que nos permite um delineamento de resposta, ao menos, provisório para o questionamento anterior, Fischbein (1993, p. 144) indica ainda uma outra indagação, e que envolve uma resposta não trivial, ao interrogar que "o curso de um processo de raciocínio é determinado por uma construção conceptual ou vice-versa?".

As argumentações de Fischbein dão indícios para uma resposta, ao menos provisória, da nossa primeira pergunta. De fato, ele esclarece que "o fenômeno é tão complexo que não é possível uma resposta definitiva. A hipótese mais aceitável é a de ser que em cena, comparecem cadeias conceptuais ativas de conhecimento com fontes de saberes imaginativos" (FISCHBEIN 1993, p. 144). Dessa forma, a partir de suas ponderações, podemos depreender que, quer seja um raciocínio de base lógico-formal ou o imaginativo, de natureza intuitiva, a construção conceptual de um indivíduo, elaborada, reelaborada e construída, de modo idiossincrásico, será determinante para a evolução/progresso do pensamento mobilizado em situação.

$\mathrm{Na}$ próxima seção retornaremos aos argumentos próximos desses dois questionamentos, considerando situações específicas, tendo em vista o ensino do Cálculo Diferencial e Integral. Observamos ainda que, quando consideramos a atividade de um expert (seja um matemático, físico, engenheiro, etc.), urge distinguir formas de pensamento especializadas, elevadas e complexas. Tais habilidades cognitivas são descritas por Fischbein ao mencionar que: 
Um dos aspectos marcantes do expert (e em particular do matemático) é a capacidade de converter em mensagens relevantes, todavia, inicialmente cifradas e/ou obscuras. E todo o processo intelectivo ocorre, de modo aparentemente automático, antecedendo uma análise sistemática maior de depuração. Por fim, os resultados surgem de modo intuitivo, a partir de uma avaliação global relativizada.

Pouco mais adiante, Fischbein (1987, p. 63) diferencia que "intuições antecipatórias envolvem a resolução preliminar de um problema. Enquanto que uma intuição afirmativa representa uma atitude cognitiva estável, em relação a uma situação mais geral ou comum". Diferentemente das intuições afirmativas, que envolvem a manifestação da aceitação preliminar de determinado fato ou propriedade autoevidente, as intuições antecipatórias surgem como descobertas, como a solução de um problema, de modo tácito e repentino, consequência de um esforço de investigação indicativo de uma mudança de estádio cognitivo mais elevado.

Em relação à classe de intuições antecipatórias, Fischbein (1987, p. 63) acrescenta que "existe, de modo geral, certo grau de necessidade (não sentido de modo subjetivo) de controle analítico externo". A confrontação entre uma certeza intrínseca e uma demanda externa que impõe a verificação pode produzir situações psicológicas (às vezes conflitivas, como o exemplo da fig. 1) interessantes. Diferentemente das classes de intuições anteriores, o locus de manifestação ou ocorrência das intuições antecipatórias é o contexto da resolução efetiva de um problema particular.

Reparemos, todavia, que os dados de um problema específico podem ser ou não, determinantes em sua manifestação. Com efeito, as conclusões que seguem, com origem em momentos iluminatórios - chamadas de intuições antecipatórias - não são equivocadamente e especialmente condicionadas por dados de um problema particular. "Elas dependem de um maior grau pessoal de segurança, atitudes cognitivas estáveis" (FISCHBEIN, 1987, p. 64). Por fim, ao decorrer do processo investigativo, poderão ocorrer intuições conclusivas que "sumarizam uma estrutura global, visão estruturada e ideias básicas da solução de um problema, previamente elaborado".

De modo sistemático, o autor propõe a descrição que mostramos na figura 2. Podemos falar agora de intuições no contexto da resolução de problemas no contexto do ensino de Cálculo. A exploração metodológica das categorias indicadas abaixo pode diminuir a predominância da hegemonia do pensamento algoritmo-estrutural, rotineiramente fortalecido na academia (ALVES, 2011). Assim, com origem num esquema mnemônico indicado por Fischbein (1987, p. 64), propugnamos determinadas alterações, na medida em que, ensejamos adaptar a natureza das categorias intuitivas indicadas por ele ao nosso contexto do ensino de Cálculo, em uma e em várias variáveis.

Apesar de indicar ênfase na classe de intuições antecipatórias e conclusivas na resolução de problemas, na classe das intuições afirmativas, pode ocorrer o emprego de uma estratégia específica. Bem como, após o êxito ou o fracasso de um plano de execução, com vistas à solução, as intuições afirmativas tomam espaço, mais uma vez, no sentido de fornecer o "feeling" que impulsionará, 
possivelmente, o solucionador na resolução do mesmo problema ou de um novo problema, com um nível mais sistematizado que o anterior.

Figura 2 - Classificação de categorias intuitivas propostas por Fischbein (1987, p. 64).

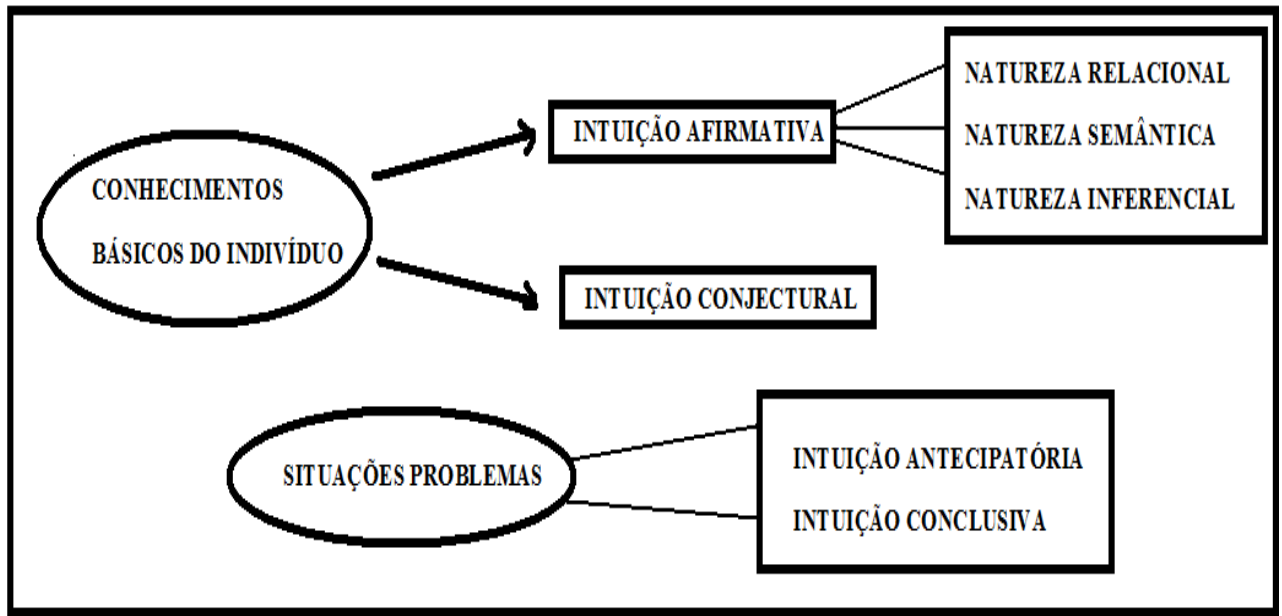

(Fonte: Adaptação do esquema proposto por Fischbein (1987))

Antes de concluirmos, cabe observar o papel das intuições conjecturais, emitida por experts, todavia, a História da Matemática registra o entendimento e as ideias de jovens matemáticos, não tidos à época como experientes, e, sim, principiantes; mas que, todavia, formularam conjecturas dignas de um expert (ou matemático mais experiente) (BELL, 1951; KLINE, 1972). No próximo segmento abordaremos algumas situações de aplicação das noções discutidas nos parágrafos anteriores.

\section{EXEMPLO DE APLICAÇÃO NO CÁLCULO EM UMA VARIÁVEL REAL E EM VÁRIAS VARIÁVEIS}

Nessa seção, indicaremos algumas situações intrinsecamente condicionadas pelo uso de teoremas que descrevem a convergência de integrais impróprias ou, chamadas também de integrais generalizadas. O contexto de sua apresentação é direcionado às estratégias de solução de problemas no ensino do Cálculo. Nas situações que doravante discutiremos, são apoiadas em elementos que valorizam a visualização e a percepção de propriedades gráfico-geométrica de objetos matemáticos, tendo como auxílio a tecnologia.

Vejamos o seguinte exemplo que envolve o enunciado standard dos compêndios de livros de Cálculo: avaliar a integral $\int_{0}^{1} x \cdot \ln (x) d x$. Vale patentear o caráter arbitrário, indicador de uma única via de ação. Tal ação, envolve escrever:

$\int_{0}^{1} x \cdot \ln (x) d x=\lim _{t \rightarrow 0^{+}} \int_{t}^{1} x \cdot \ln (x) d x=\lim _{t \rightarrow 0^{+}}\left(1 / 2 x^{2} \cdot \ln (x)-1 / 2 x\right)_{t}^{1}=-1 / 4-1 / 2 \lim _{t \rightarrow 0^{+}}\left(t^{2} \cdot \ln (t)\right)$.

No que segue, a regra de L'Hospital é empregada e, assim, inferimos uma conclusão. Por outro lado, vamos inserir outros elementos que podem promover o surgimento de categorias intuitivas que tencionamos evidenciar e afetam a própria velocidade da investigação, com base na interação entre aluno e o professor. Nesse sentido, formulamos: Com base no comportamento dos gráficos 
das funções $f(x)=x, g(x)=\ln (x)$. Decidir sobre o comportamento da integral $\int x \cdot \ln (x) d x$ indicando uma região em que converge e outra região em que podemos contar com sua divergência, com base na figura 3.

No cenário que indicamos na figura 3, destacamos caracteres qualitativosvisuais. A exploração e a manipulação do seletor são livres no software GeoGebra, o que proporciona o caráter dinâmico da situação e a possibilidade de elaboração de conjecturas que se enquadram na classe de intuições antecipatórias que são a solução preliminar de um problema específico.

Ora, com o amparo do quadro numérico, na figura 3, o solucionador de problemas pode depreender que na região da área que corresponde à seguinte integral $\int_{0}^{1} x \cdot \ln (x) d x$, os valores e contribuições de área não tendem a crescer de modo ilimitado. Por outro lado, a região da área (abaixo da curva) que corresponde à seguinte integral $\int_{1}^{\infty} x \cdot \ln (x) d x$, constata-se o crescimento ilimitado das contribuições numéricas. Nessa fase preliminar, antes do emprego efetivo de um modelo formal, descrito por inferências, semelhante ao que indicamos em $\left({ }^{*}\right)$, não se torna ainda necessário.

Figura 3 - Cenário de visualização proporcionado pelo GeoGebra e a produção de conjecturas antecipatórias.

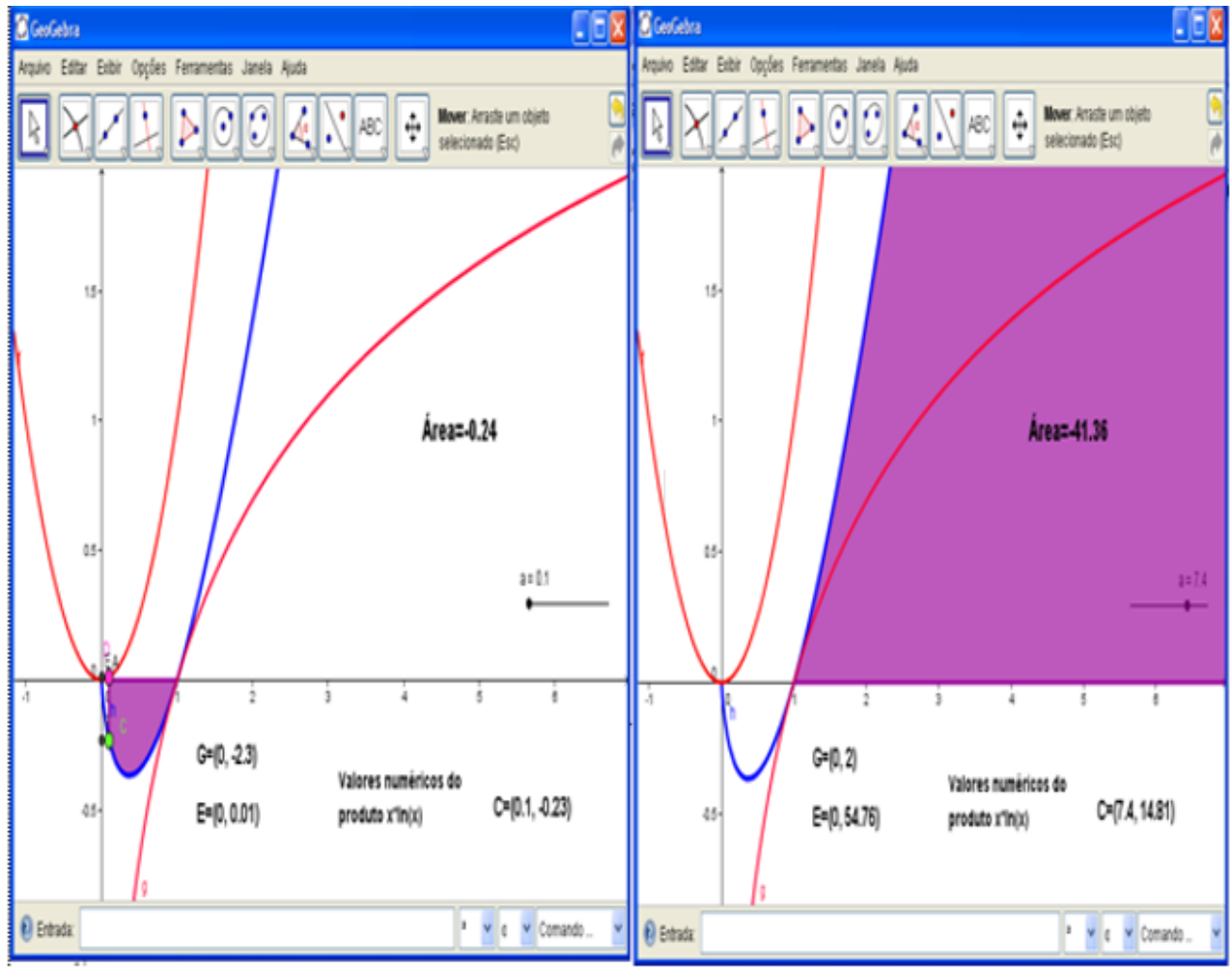

(Fonte: Elaboração do autor)

Por outro lado, a elaboração de intuições antecipatórias é condicionada, a partir da região ou intervalo $[a, b] \subset I R$, no qual, o solucionador sente a indicada ou formulada uma conjectura plausível, o professor estimula o emprego 
efetivo das estratégias adequadas. Em qualquer expediente empregado, o uso da definição formal de integral imprópria é compulsório.

Todavia, as inferências de ordem lógicas podem ser interrompidas diante do limite $1 / 2 \cdot \lim _{t \rightarrow 0^{+}}\left(t^{2} \cdot \ln (t)\right)$. O reconhecimento do padrão algébrico é determinante num ensino que restringe às habilidades algébrico-manipulatórias do estudante (ALVES, 2011, p. 239). Por outro lado, o professor poderá, nesse momento, instigar os solucionadores de problemas em observar o gráfico (em cor azul) da função indicada por $h(x)=x^{2} \cdot \ln (x)$. Na figura 3 , seu gráfico em azul, pode ser inspecionado e, como base nessa exploração visual, outras conjecturas podem ser elaboradas, no que concerne à sua existência do limite no ponto (que vale zero!).

Mais uma vez, promovemos a produção de intuições antecipatórias, com a análise numérica do produto $x^{2} \cdot \ln (x)$. O software GeoGebra possibilita a manifestação gráfico-geométrica da indeterminação do tipo $0^{+} \cdot(-\infty)$ (ALVES, 2012, p. 9), o que pode ser averiguado nos gráficos (em cor vermelha) da figura 3. Mais uma vez, podemos evitar o tratamento mecânico e irrefletido dos alunos referente ao procedimento analítico padrão indicado por $x^{2} \cdot \ln (x)=\ln (x) / 1 / x^{2} \therefore \lim _{x \rightarrow 0^{+}} \ln (x) / 1 / x^{2}=\lim _{x \rightarrow 0^{+}}(1 / x) /\left(-2 / x^{3}\right)=\lim _{x \rightarrow 0^{+}}\left(-x^{2} / 2\right)=0$.

Figura 4 - Descrição qualitativa do comportamento de convergência em 2D e 3D.

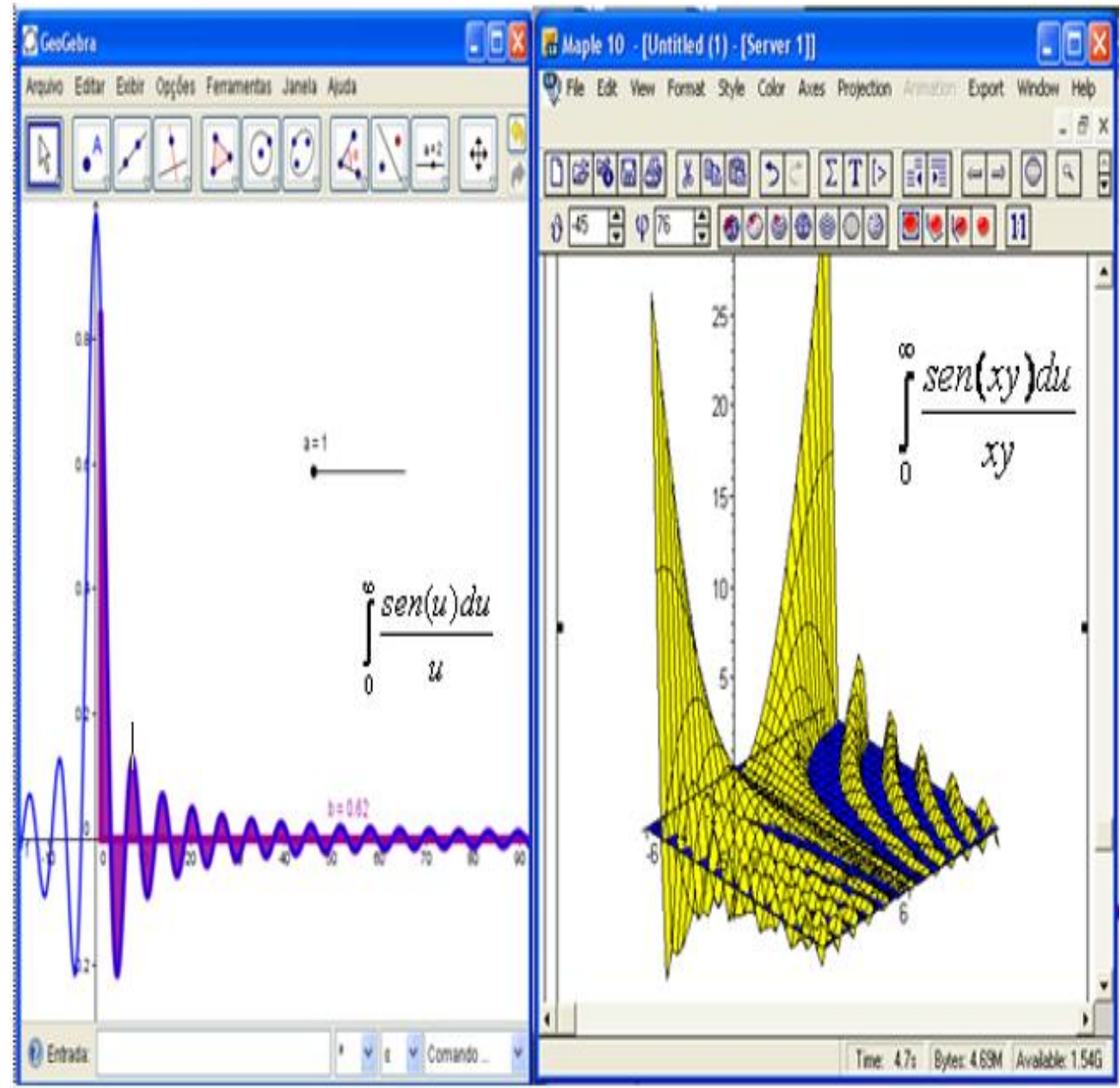

(Fonte: Elaboração do autor) 
Por fim, consideremos as seguintes integrais impróprias $\int_{0}^{\infty} \operatorname{sen}(u) / u d u$ e $\int_{0}^{\infty} \operatorname{sen}(x y) /(x y) d u$, onde fizemos a substituição $u=x y$. Na figura 4 acima, proporcionamos o entendimento quanto ao caráter de convergência da primeira integral (com representação 2D). A formulação de conjecturas, a partir da visualização e comparação dos gráficos abaixo, permitem evitar o predomínio de intuições afirmativa inferenciais. De fato, a partir da sensação e impressão da convergência da primeira (contribuições de área tendem a diminuir), o solucionador pode inferir que a mesma propriedade é imediatamente aplicável à segunda integral, tendo em vista o comportamento das contribuições de volume (representação 3D). A comparação dos gráficos (abaixo) impulsionará uma investigação pormenorizada para o entendimento (dinâmico) da noção de convergência.

O Teorema da Função Implícita - TFI ocupa um papel fundante no Cálculo (BORTOLOSSI, 2002; GUIDORIZZI, 2010; STEWART, 2001) e em Análise no $I^{n}$ (APOSTOL, 1967; LIMA, 2009). Por outro lado, em nossos trabalhos identificamos as potencialidades do uso da tecnologia (ALVES, 2014b). Nesta seção, indicaremos elementos de uma abordagem, sob o viés da atividade de resolução de problemas, que contempla, do ponto de vista da mediação didático-metodológica, a exploração adequada das categorias intuitivas descritas por Fischbein, nos parágrafos anteriores.

Nosso exemplo foi retirado de Guidorizzi (2010, p. 242). No enunciado do problema, são fornecidas equações implícitas que determinam o sistema $\left\{x^{2}+z^{2}=1, \mathrm{y}^{2}+z^{2}=1\right\}(* *)$.

Sob o viés condicionado pelo algebrismo, o autor pede para se expressar $d y / d x$ e $d z / d x$, em termos de $x, y$ e z. Requisita determinar, ainda, um par de funções $y=y(x)$ e $z=z(x)$ dadas implicitamente por (**).

A rotina ou estratégia de resolução é condicionada, nesse caso, pelo conhecimento ou não das condições formais e o que prevê o TFI. Quando restringimos nosso ensino a uma abordagem condicionada e afetada pelo viés pouco atualizado e peculiar dos autores de livros de Cálculo, perdemos a oportunidade de proporcionar a produção de uma série de intuições atinentes ao exercício proposto. Entretanto, seguindo uma abordagem característica da resolução e descoberta de problemas, explicitamos, num momento inicial, o reconhecimento da região do espaço $I R^{3}$, na qual evocamos o uso do TFI (fig. 5).

Antes de qualquer expediente (precipitado) ou argumento de natureza algébrica, o solucionador de problemas pode explorar os gráficos abaixo (figura 5), como ainda deparar situações em que podemos formular intuições afirmativas. De fato, sentenças proposicionais do tipo "as curvas produzidas pela intersecção de dois ou três cilindros é diferenciável", na medida em que empregamos o aparato computacional, viabilizará a investigação visual e perceptual da última sentença proposicional. 
O CAS Maple proporciona a produção de gráficos no $I R^{3}$ inexequíveis, quando restringimos nossa mediação ao quadro negro. Ademais, a curva (em vermelho) permite a localização topológica de pontos e, sobre eles, de acordo com determinadas restrições impostas no enunciado do TFI, poderemos ou não garantir a existência de um "pedaço" (BORTOLOSSI, 2002, p. 316) de um gráfico de função, determinado em termos implícitos. Trazemos também outra situação, com o acréscimo de outro cilindro $x^{2}+y^{2}=1$, o que proporciona a produção de conjecturas sobre o sistema que indicamos no canto inferior direito (com três equações descritas de modo implícito) (figura 5).

Por meio de derivação implícita, se obtém das taxas de variação $\frac{d z}{d x}=-\frac{x}{z}$ e $\frac{d z}{d y}=-\frac{y}{z}$. De acordo com a definição de derivada parcial, determinamos as seguintes retas $z=-x+\sqrt{2}$ e $z=-y+\sqrt{2}$. Por fim, levando em condição as restrições do TFI, determinamos uma vizinhança indicada por $(x-\sqrt{2} / 2)^{2}+(y-\sqrt{2} / 2)^{2}+(z-\sqrt{2} / 2)^{2}=1$. Com amparo na visualização, podemos promover a significação geométrica para os símbolos $\frac{d z}{d x} \mathrm{e} \frac{d z}{d y}$ correspondentes às declividades de retas tangentes, na direção de cada eixo (ver figura 6).

Figura 5 - Descrição gráfico-geométrica da região no espaço que determina a curva de intersecção de superfícies e o uso do TFI no ensino do Cálculo em várias variáveis 


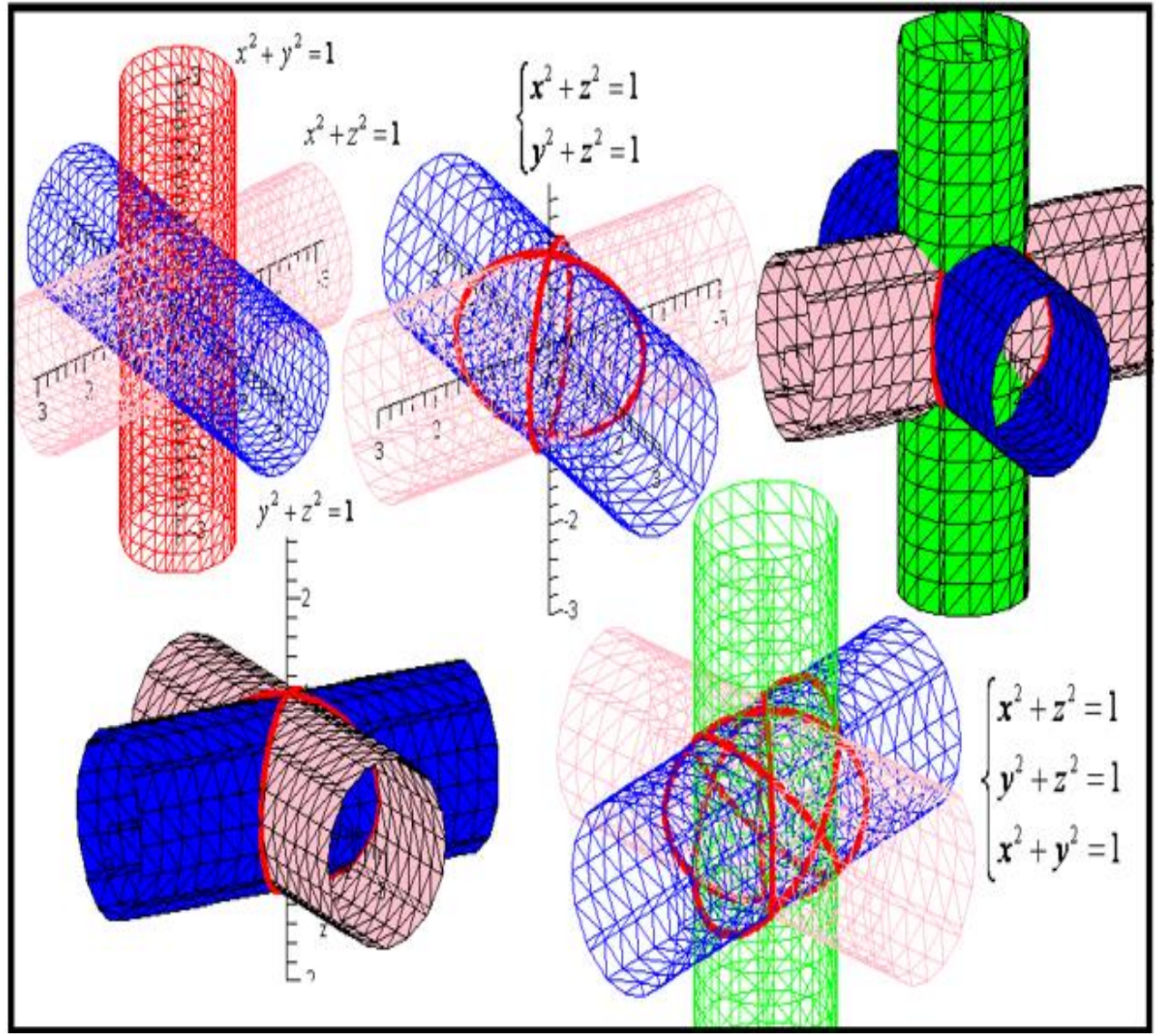

(Fonte: Elaboração do autor)

Observamos que o estudante deverá compreender as relações $\frac{d z}{d x}(\sqrt{2} / 2, \sqrt{2} / 2)=\left.\frac{\partial z}{\partial x}(\sqrt{2} / 2, \sqrt{2} / 2)\right|_{y=\frac{\sqrt{2}}{2}}$ e $\frac{d z}{d y}(\sqrt{2} / 2, \sqrt{2} / 2)=\left.\frac{\partial z}{\partial y}(\sqrt{2} / 2, \sqrt{2} / 2)\right|_{x=\frac{\sqrt{2}}{2}}$ das derivadas parciais. Fato que se mostra desconsiderado por Guidorizzi (2010, p. 242). Por fim, podemos promover a mobilização de determinadas intuições conclusivas (comparar as figuras 5 e 6 ), na medida em que, ao solucionar o problema anterior, pelo emprego do TFI, questionamos as regiões de interseção, na quais, não é aplicável o referido teorema. A visualização permite o entendimento do caráter local de sua aplicação, tendo em vista a determinação da região em que o teorema prevê a existência do gráfico de uma função (ver vizinhança do ponto) (figura 6).

Figura 6 - O software CAS Maple proporcionar a elaboração de um cenário de visualização para a percepção e identificação de elementos qualitativos envolvidos na situação (do ponto de vista local e global). 


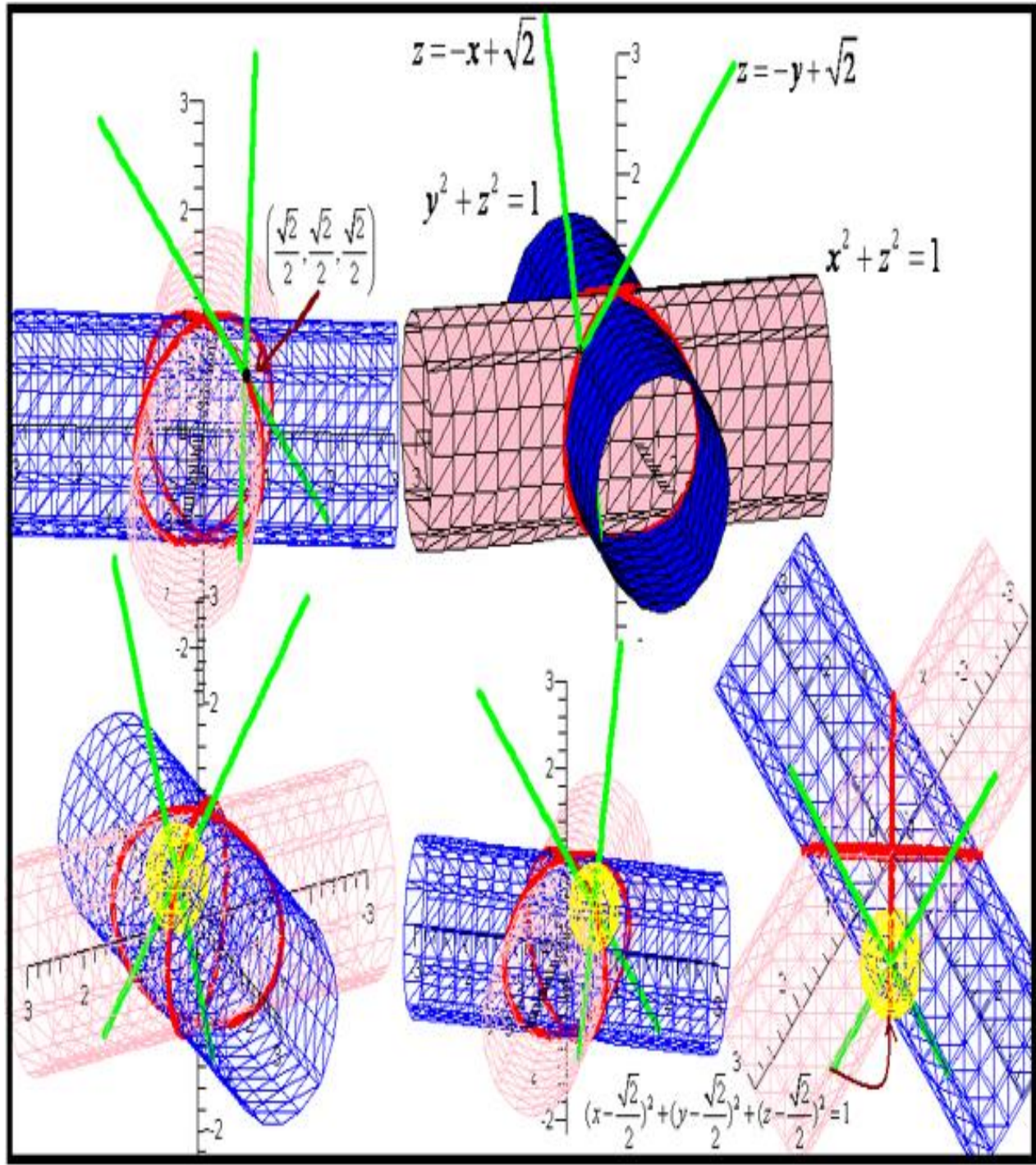

(Fonte: Elaboração do autor)

\section{CONSIDERAÇÕES FINAIS}

Alguns chamam de faculdade cognitiva. Outros denominam evento cognitivo. Qualquer que venha a ser sua denominação eventual, o que conseguimos ratificar é a falta de consenso e a "multiplicidade de definições" (FISCHBEIN; TIROSH \& MELAMED, 1981, p. 491) que não conseguem descrever com eficiência, qualquer fenômeno cognitivo amparado pela intuição. Por outro lado, a classificação/descrição de modo hierárquico, na acepção de Fischbein (1987), permite extrair fortuitas implicações e aplicações diferenciadas no ensino no contexto do ensino do Cálculo em Uma e a Várias Variáveis (ALVES, 2014b).

Nesse sentido, assinalamos, ao decorrer desse escrito, os arcaísmos ainda presentes na abordagem dos principais compêndios de Cálculo (STEWART, 2004; SWOKOWSKI, 1983). O fato é que, a partir desses compêndios, os professores que atuam na academia, extraem concebem e modelizam situações de ensino nos cursos de graduação, ainda no estilo da Matemática Moderna (FISCHBEIN, 1969; 
KLINE, 1985). Tendo em vista uma abordagem que torna preponderante a algebrização das rotinas, e a correspondente formalização estruturante precoce dos argumentos (ARTIGUE, 1998), podemos suspeitar de uma ineficiência, no sentido oposto ao das situações estruturadas semelhantes como as que discutimos ao longo do texto, que concedem posição distinguida para a visualização.

É oportuno acentuar que todas as categorias intuitivas descritas admitem profundo grau de subjetividade e são de difícil identificação ao decurso da ação dos estudantes em situação. Assim, a mediação (estímulo) de um agente externo, de modo adequado, é fator primordial para o surgimento e a evolução adequada, bem como inadequadas ou concepções que contrariam a intuição (FISCHBEIN, 1977 ; 1978; 1993) e podem concorrer para o erro. Por exemplo, vale observarmos determinadas concepções equivocadas e informais de estudantes, a respeito de certos conceitos científicos, preservadas durante boa parte da vida do estudante. Em muitos casos, o marco inicial da aquisição de tais concepções evidencia o papel importante da intuição na formulação das primeiras impressões e entendimentos, o que se coaduna com o que preceitua Boutroux (1908).

Nesse sentido, a ação/mediação didática deverá envidar esforços no sentido de transformar intuições afirmativas, que dizem respeito a um stádio mental, não necessariamente imbuído da resolução pormenorizada e compreensão de um problema particular, em intuições antecipatórias e conclusivas, que envolvem esforço e interesse do estudante, com vistas à produção de um novo entendimento, no âmbito do ensino do Cálculo. 


\title{
INTUITIVE CATEGORIES FOR TEACHING OF CALCULUS: DESCRIPTION AND IMPLICATIONS FOR IT'S TEACHING
}

\begin{abstract}
The learning of an individual has starting point, based on a logical-formal reasoning or intuitive reasoning? If the answer to this question points toward the intuitive reasoning, arises a second question: But what is even an intuitive reasoning? With attention to answer this later question, and others that arises, naturally, adopts the perspective of Fischbein (1987), in relation to a proposed description of categories for the intuition. Thus, emphasis is places on its significance in the context of problem solving about the Differential and Integral Calculus. The consideration of such intuitive categories acquires importance in that it proposes an approach that relies on technology in order to explore the visualization and therefore the production of propositional sentences, derived from an established relationship between subject/mathematician. Finally, the work explores some examples (generalized integral and the implicit function theorem) and indicate perspectives that act to soften the arbitrary effects of the formalism.
\end{abstract}

KEYWORDS: Intuition. Calculus. Problem resolution. Intuitive categories. 


\section{REFERÊNCIAS}

ALVES, Francisco. Regis. V. \& BORGES NETO, Herminio. A contribuição de Efrain Fischbein e a formação do professor. Revista Conexões, Ciência e Tenologia, v. 5, no 1, p. 38-54, 2011.

ALVES, Francisco. R. V. Aplicações da Sequência Fedathi na promoção das categorias do raciocínio intuitivo no Cálculo a Várias Variáveis. Fortaleza: UFC, 2011, 399 p. Tese (Doutorado) - Programa de Pós-graduação em Educação Brasileira, Universidade Federal do Ceará, Fortaleza, $399 f$.

ALVES, Francisco R. V. Discussão da noção de integral imprópria com o auxílio do GeoGebra. Conferência Latinoamericana do GeoGebra. 2012, p. 1-8.

Disponível em: http://www.GeoGebra.org.uy/2012/home.php. Acessado em: 18 maio. 2013.

ALVES, Francisco R. V. INSIGHT: Descrição e possibilidades de seu uso no ensino do Cálculo. VYDIA Educação, v. 32, na 2, p. 149 -161, 2012.

ALVES, Francisco. Regis. V. Engenharia Didática para o Teorema da Função Implícita: análises preliminares e a priori. Revista Brasileira de Ensino de Ciência e Tecnologia, v. 7, no 3, p. 148 - 168, 2014a.

ALVES, Francisco. R. V. Técnica computacional para o ensino de Matemática. Revista de Educação Matemática e Tecnológica Iberoamericana. v. 5, no 2, 1 16. 2014b.

ALVES, Francisco. Regis. V. The winning number: an heuristic approach with the GeoGebra's help. Acta Didactica Naposcencia, v. 9, no 2, p. 1 - 12, 2016.

APOSTOL, Tom. Calculus. v. 2, New York: Handcover, 1967. 
BELL, Erick. T. Mathematics: Queen and servants of Science. New York: Mc-Grill Hill Company. 1951, $458 f$.

BOUTROUX, E. Études d'histoire de la Philosophie, Paris: Félix Alcan Éditeur, 1908.

BORTOLOSSI, Humberto. Cálculo a Várias Variáveis: uma introdução à otimização. São Paulo: Coleção Matmídia, 2002, $617 f$.

BUNGE, Mario. Intuitición y Rázon, 1ạ édition, Buenos Aires: Delbolsíllo, 1996.

CHOQUET, Gustave. What is Modern Mathematics? England: Educational Exploring Reading. 1963, 54f.

ERNEST, Paul. The Phylosophy of Mathematics Education. London: Taylor \& Francis Ltd, 1991.

FISCHBEIN, E. Enseignement Mathématique et Développement Intellectuel. In: Educational Studies in Mathematics. v. 38, n. 11, p. 290-306, 1969.

FISCHBEIN, Efrain. Image and Concept in learning mathematics. In: Educational Studies in Mathematics. v. 8, n. 4, p. 153-165, 1977.

FISCHBEIN, Efrain. Schemes virtuels et Schemes actifs dans I'apprentissage des Sciences. In: Revue Française de Pédagogie. № 45, n. 15, 1978, p. 119-125.

FISCHBEIN, Efrain ; TIROSH, Dina. \& MELAMED, U. Is it possible to mesure the intuitive acceptance of a mathematical statement? Educational Mathematics Studies, v. 3, n. 23, p. 491-512, 1981. 
FISCHBEIN, Efrain. The Theory of Figural Concepts. Educational Studies in Mathematics. v. 24, n. 22, p. 139-162, 1993.

FISCHBEIN, Efrain. Intuition and schemata in Mathematical Reasoning. Educational Studies in Mathematics. v. 24, n. 22, p. 11-50, 1999.

GUIDORIZZI, H. Um curso de Cálculo, vol.2, Rio de Janeiro: Livros Técnicos e Científicos, 2010.

HADAMARD, Jaques. The Psychology of Invention in Mathematical field. New York: Dover Publication. 1945.

HERSH, Reuben. What is Mathematics, Really? New York: Oxford University Press, 1997.

KLINE, Morris. Mathematical thought from Ancient and Modern Times. v. 1, Oxford: Oxford University Press, 1972.

KLINE, M. Mathematics and the search for the knowledge, Oxford: University Press, 1985.

LIMA, E. L. Curso de Análise, v. 2, Rio de Janeiro: Instituto de Matemática Pura e Aplicada, 2009.

OTTE, M. O formal, o social e o subjetivo: uma introdução à Filosofia e a Didática da Matemática, São Paulo: UNESP Editora, 1991.

POINCARÉ, Henri. The foundations of Science. New York: The Science Press. 1921. 
RUSSELL, Bertrand. Introduction to Mathematical Philosophy. New York: Dover inc. 1993. 214f.

STEWART, J. Cálculo, v. 2, 4a edição, São Paulo: Pioneira Thompson Learning, 2004.

SWOKOWSKI, Earl. W. Calculus with Analytic Geometry. Boston: Prindle, Weber e Schmidt, 1983.

Recebido: 18 mai. 2013

Aprovado: 12 out. 2016

DOI: $10.3895 /$ rbect.v9n3.1538

Como citar:

ALVES, F. V. Categorias intuitivas para o ensino do Cálculo: descrição e implicações para o ensino.

Revista Brasileira de Ensino de Ciência e Tecnologia, v. 9, n. 3, 2016. Disponível em:

<https://periodicos.utfpr.edu.br/rbect/article/view/1538>. Acesso em: xxx.

Correspondência:

Direito autoral: Este artigo está licenciado sob os termos da Licença Creative Commons-Atribuição 4.0 Internacional. 